PJOS 5(1), 2013

\title{
Editorial introduction: The return of sound symbolism
}

\author{
Jordan Zlatev
}

This special issue of The Public Journal of Semiotics presents four contributions devoted to the phenomenon of sound symbolism: the motivated, non-arbitrary relationship between sound shapes and meanings in language. While having a long history, going back at least to Plato, for most of the 20th century this phenomenon was rejected, downplayed and even ridiculed: "Discussions of sound symbolism in natural languages often trigger laymen's curiosity but linguists' skepticism" (Hamano, 1998: 3). Saussure's "primordial principle" of the arbitrariness of the linguistic sign was typically considered an unquestionable cornerstone of language and linguistics. But, as known, all dogmatic theses bare within them the seeds of their antitheses.

Jakobson (1965) explicitly objected to what he called the "the Saussurean dogma", and pointed out the relevance of the Peircian concepts of iconicity and indexicality for language, along with the key point that these and symbolicity need not be mutually exclusive: "It is not the presence or absence of similarity or contiguity between the signans and signatum, nor the purely ... habitual connection between both constituents, which underlies the division of signs into icons, indexes and symbols, but merely the predominance of one of these factors over the others" (ibid: 26). Still, it was not until the publication of the collection of papers in the volume Sound symbolism (Hinton, Nichols \& Ohala, 1994) that the case for substantial non-arbitrariness in speech was firmly made. Different classes of ideophones - conventionalized expressions with sound-meaning correspondences in a single sensory modality like bang, or across modalities like Japanese sutasuta (approximately: moving quickly) - were recognized to be present in all languages, albeit with cross-linguistic differences. A number of psychological motivations for sound symbolism have been proposed, including the socalled frequency code (Ohala, 1994): low vocal frequency serves as a biological signal of large body size and dominance, and conversely: high frequency indicates small size and submissiveness. This contrast can then be iconically mapped to expressions signifying large and small qualities, as in French grand vs. petit. Such proposals fall in a tradition of research active since Köhler (1929), showing that speakers spontaneously recognize such mappings, and utilize them in comprehension and learning, even if the forms of their own language lack the corresponding contrasts. To counter skepticism, it has become essential to use both qualitative and quantitative analyses, including statistics.

In short, sound symbolism has become a hot research agenda for semiotics, linguistics and cognitive science, and their emerging synthesis known as cognitive semiotics (Zlatev, 2012). Questions such as the following are being asked: What is the semiotic nature of different sound-meaning relations: iconic or indexical, metaphoric or metonymic, or combinations of these? In terms of iconicity: is this a matter of primary or secondary (Sonesson, 1997)? How and why do the degrees and forms of sound symbolism differ across languages? What exactly is their functionality: what advantages does sound symbolism offer speakers in terms of learning and communication, and how does this balance off against relative arbitrariness? These are exactly the kinds of questions asked by the authors of the papers in this special issue.

The first two articles employ the methods of linguistic typology and the latter two: of experimental psychology. A motivated mapping between sound shapes and spatial 
deixis is investigated by Johansson \& Zlatev, by considering a fairly large sample of languages and comparing prior predictions, with results showing support for a version of the frequency code. Akita studies the ways in which onomatopoetic words like grumble and jingle are semantically extended in three East-Asian languages, Chinese, Japanese, Korean, and English, and finds that differences correlate with factors such as how referentially specific the words are, and how close to the grammatical "core" of the sentence they are (with verbs being more central than adverbs). This implies that sound symbolism is tightly interwoven with core properties of semantics and grammar. Cuskley provides an informative overview of psychological research in sound symbolism, supporting a plausible evolutionary explanation: "the combination of systematicity and iconicity at the phonemic level served to bootstrap the evolution of an arbitrary vocabulary, and that iconicity is still used to generate new forms, maintaining a subset of language which is highly learnable" (ibid: 41). In her own experimental study, she demonstrates that speakers match nonce forms with visually perceived motion in a nonarbitrary manner, e.g. with vowels mapped to slower motion, and consonant reduplication to faster motion. Finally, Abelin studies Swedish positive and negative interjections like usch ('ugh') primed with congruent or non-congruent emotional prosody. The results of the study support the hypothesis that the appropriate emotional prosody is part of speakers' linguistic knowledge of these expressions.

I wish to thank the authors and anonymous reviewers for their diligence and patience in preparing the final versions of these papers, going through several steps of revision. I also take the opportunity to thank founder and previous editor of PJOS, Prof. Paul Bouissac for the trust in letting us at Lund University continue publishing this valuable multidisciplinary journal devoted to the study of meaning across different semiotic resources and methods. Tom Wysocki and Mats Andrén deserve credit for making the transition from the previous to the present form of the journal a smooth one. This is the first issue published of the "new PJOS", but several others, both general and thematic like the present, are in progress. Readers, stay tuned!

\section{References}

Jakobson, R. (1965). Quest for the essence of language. Diogenes, 13, 21-38.

Hamano, S. (1998). The Sound-Symbolic System of Japanese. Stanford, CA: CSLI Publications.

Hinton, L., Nichols, J. \& Ohala J. (1994). Sound symbolism. Cambridge: Cambridge University Press.

Köhler, W. (1929). Gestalt Psychology. New York, NY: Liveright.

Ohala, J. J. (1994). The frequency code underlies the sound-symbolic use of voice pitch. In L. Hinton, J. Nichols and J.J. Ohala (Eds.) Sound symbolism (pp. 325-347). Cambridge: Cambridge University Press.

Sonesson, G. (1997). The ecological foundations of iconicity. In I. Rauch \& G.F. Carr (Eds.), Semiotics Around the World: Synthesis in Diversity (pp. 739-742). Berlin \& New York: Mouton de Gruyter.

Zlatev, J. (2012). Cognitive semiotics: An emerging field for the transdisciplinary study of meaning. The Public Journal of Semiotics 4(1), 2-24. 